\title{
Combining direct coronary artery surgery with internal mammary artery implants
}

\author{
GRAEMEL. HAMMOND and IAN MCMILLAN \\ Department of Surgery, Yale Medical School and the Cardiac Surgical Service, Yale-New Haven Hospital \\ and the Cardiac Surgical Unit, Southampton Chest Hospital, Southampton, England
}

The reasons for combining direct coronary artery surgery with internal mammary artery implants are discussed. A case typifying this problem is presented. It is concluded that, in certain instances, maximal myocardial protection could be provided by combining direct coronary reconstructive surgery, in order to increase immediate protection, with internal mammary artery implants, in order to provide long-term protection.

The most frequently used operation for treating coronary artery disease presently is the internal mammary artery implant procedure. This operation is relatively easy to perform, does not usually require a pump oxygenator and in selected cases is an effective means of bringing blood to the ischaemic myocardium (Effler, Groves, Sones, and Shirey, 1963). A drawback to this operation, however, is that vascular implants require six months (Provan, Hammond, and Austen, 1966) before a significant increase in myocardial blood supply can be detected. Consequently, a heart which is maximally stressed from coronary artery disease is required to accept the extra metabolic load of major surgery, depressant effects of anaesthesia and counter-myocardial irritant drugs and the small but definite destruction of myocardial tissue which occurs with implantation without any immediate improvement in circulation. This disadvantage results in the $5 \%$ operative mortality rate reported for single internal mammary artery implants (Vineberg and
Walker, 1964) and the $8 \%$ operative mortality rate reported for double internal mammary artery implants (Favaloro, 1968a).

In an effort to improve this situation we have adopted a more aggressive approach to this problem and now, in certain instances, combine internal mammary artery implants with direct coronary reconstructive procedures. The following case represents the problem and the reason for this approach.

\section{CASE REPORT}

J. S. is a 50-year-old diabetic male machinist. Ten years ago he suffered a myocardial infarction. Since then he has had progressive angina and six months ago he had to stop work. Pre-operatively he developed angina after walking 30 feet $(9 \cdot 1 \mathrm{~m}$.) and was taking approximately 40 nitroglycerin tablets per week. Physical examination was unremarkable except for absent pedal pulses.

The resting electrocardiogram was within normal limits, but he had a markedly positive Master's test

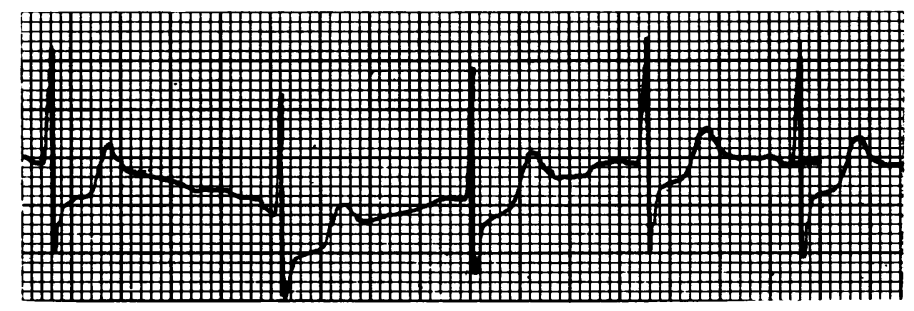

FIG. 1. Lead V4 of pre-operative Master's test showing $5 \mathrm{~mm}$ of $S-T$ depression. The patient has significant angina at 12 steps causing termination of the test. 
(Fig. 1). Selective coronary cinéangiography indicated severe triple vessel disease with collateralization of the anterior descending artery from the proximal branch of the right coronary artery. There was a $90 \%$ occlusion of the proximal left coronary artery and proximal anterior descending artery with diffuse disease distally in the anterior descending and circumflex arteries. There was a $50 \%$ occlusion of the right coronary artery proximally and a $95 \%$ occlusion $5 \mathrm{~cm}$. from its origin.

At surgery, the heart was exposed through a median sternotomy and the angiographic findings were confirmed except that, as usual, the disease appeared worse than was represented angiographically. The anterior descending and circumflex coronary arteries were so heavily calcified that a direct anastomosis to these vessels could not be made. The right coronary artery also was heavily calcified but the posterior descending branch was soft and appeared relatively free of disease.

Before revascularization surgery was performed coronary sinus lactate measurements were determined. The right internal mammary artery was implanted into the anterior left ventricle and the left internal mammary artery was implanted into the posterior surface of the left ventricle. The proximal end of a saphenous vein graft was anastomosed to the side of the ascending aorta and, with the patient supported by cardiopulmonary bypass, the distal end was anastomosed to the proximal portion of the posterior descending branch of the right coronary artery. Coronary sinus lactate determinations were again made. The pre-revascularization lactate was $57.8 \mathrm{mg}$./ $100 \mathrm{ml}$. and immediately after revascularization it was $37.6 \mathrm{mg}$. $/ 100 \mathrm{ml}$.

Post-operatively there was no angina and recovery was uneventful.

\section{DISCUSSION}

A patient with severe triple coronary vessel disease is, of course, in a high-risk operative category. Consequently, anything that can be done at the time of surgery to increase the amount of blood available to the myocardium should decrease the risk of surgery, provided a safe, direct procedure is performed. Evidence in the literature indicates that direct procedures can be performed most safely to the right coronary artery (Effler, Groves, Suarez, and Favaloro. 1967). Since there appears to be a high incidence of re-occlusion with endarterectomy (Dilley, Cannon, Kattus, MacAlpin, and Longmire, 1965) and arteriotomy with patch graft angioplasty (Favaloro, 1968b), we currently employ aortacoronary artery saphenous vein bypass graft. In the present case, the vein bypass graft lowered coronary sinus lactate levels immediately by $20 \cdot 2$ $\mathrm{mg} . / 100 \mathrm{ml}$. and the Master's test reverted to normal (Fig. 2). This on-the-table improvement in myocardial blood supply should make the heart more able to stand vascular implants, as well as the extra metabolic load of surgery. Since normal coronary sinus lactate levels are 6 to $16 \mathrm{mg}$./100 $\mathrm{ml}$., the myocardium remained ischaemic despite the vein graft and therefore able to provide fertile ground for the internal mammary artery implants to take. With the natural progression of coronary artery disease in subsequent years, flow in the vein graft will probably decrease, producing ischaemia in the area of distribution of its collaterals, which, in turn, will increase demand and. theoretically, flow through the internal mammary artery implants. This combined approach provides the advantages of giving immediate protection to the heart by increasing its blood supply at the time of surgery while simultaneously providing late protection with the internal mammary artery implants.

If, however, one is able to perform double vein bypass grafts, e.g., to the right coronary artery and the anterior descending artery, the flow in subsequent years is likely to decrease less than with a single vein graft but the operative procedure is significantly lengthened and the morbidity increased so that combining double implants with

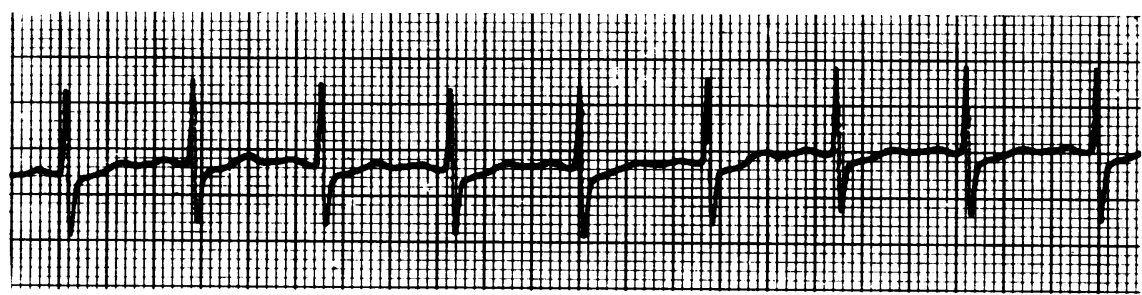

FIG. 2. Lead V4 of the Master's test before patient's discharge from hospital. Notice absence of $S-T$ depression. The test was carried to 20 steps without the onset of angina. 
double vein grafts may not be indicated. At this time we feel that double implants should be combined with direct procedures when one vein graft can be employed.

This study was supported by American Heart Association grant 67-798.

\section{REFERENCES}

Dilley, R. B., Cannon, J. A., Kattus, A. A., MacAlpin, R. N and Longmire, W. P. (1965). The treatment of coronary occlusive disease by endarterectomy. J. thorac. cardiovasc. Surg., 50, 511 .
Effler, D. B., Groves, L. K., Sones, F. M., Jr., and Shirey, E. K. (1963). Increased myocardial perfusion by internal mammary artery implant: Vineberg's operation. Ann. Surg., 158, 526.

- Suarez, E. L., and Favaloro, R. G. (1967). Direct coronary artery surgery with endarterectomy and patch-graft reconstruction: clinical application and technical considerations. J. thorac. cardiovasc. Surg., 53, 93.

Favaloro, R. G. (1968a). Double internal mammary artery implants: operative technique. J. thorac. cardiovasc. Surg., 55, 457.

- (1968b). Saphenous vein autograft replacement of severe segmental coronary artery occlusion. Ann. thorac. Surg., 5, 334.

Provan, J. L., Hammond, G. L., and Austen, W. G. (1966). Flowmeter studies of internal mammary artery function after implantation into the left ventricular myocardium. J. thorac. cardiovasc. Surg., 52, 820.

Vineberg, A., and Walker, J. (1964). The surgical treatment of coronary artery heart disease by internal mammary artery implantation: report of 140 cases followed up to 13 years. Dis. Chest, $45,190$. 